\title{
O NOME E A NATUREZA DOS ESTUDOS DO TRADUTOR
}

\author{
THE NAME AND NATURE OF TRANSLATOR STUDIES ${ }^{1}$

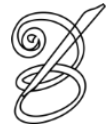 \\ Andrew Chesterman \\ Professor Emérito da University of Helsinki, Finlândia \\ chesterm@mappi.helsinki.fi \\ Traduzido por ${ }^{2}$ : \\ Patrícia Rodrigues Costa ${ }^{3}$ \\ (Doutoranda em Estudos da Tradução / PGET/UFSC) \\ Prcosta1986@gmail.com \\ Rodrigo D'Avila Braga Silva \\ (Mestrando em Estudos da Tradução, POSTRAD/UnB) \\ rodrigodavilabraga@gmail.com
}

Resumo: Uma tendência recente das pesquisas sobre Estudos da Tradução é focar explicitamente no tradutor, de alguma maneira, em detrimento às traduções de textos. Esta tendência pode ser denominada pelo termo "Estudos do Tradutor". Este artigo visa atestar que este novo enfoque é representado inadequadamente no mapa clássico proposto por Holmes. Evidências sobre esta tendência são observadas principalmente na sociologia da tradução, bem como na história da tradução e em pesquisas sobre os processos de tomada de decisão do tradutor. Um amplo esquema acerca dos Estudos do Tradutor deve abranger áreas como sociologia, cultura e cognição, tendo como enfoque as atividades do tradutor sob diferentes ângulos.

Abstract: A number of recent research tendencies in Translation Studies focus explicitly on the translator in some way, rather than on translations as texts. These trends might be grouped under the term "Translator Studies". The article argues that this new focus is inadequately represented in Holmes' classic map. Evidence of the recent trends is found especially in translation sociology, but also in translation history and in research into the translator's decision-making processes. A broad outline of Translator Studies would cover sociology, culture and cognition, all looking at the translator's agency, in different ways.

\section{Estudos do Tradutor?}

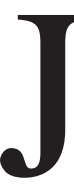

ames Holmes iniciou o seu clássico artigo (publicado em 1988 e com versão original de 1972) ressaltando que quando a ciência descobre uma nova área de conhecimento, duas consequências são possíveis. O novo campo de pesquisa pode ser incorporado a um já existente, tornando-se um ramo legítimo deste domínio ou esta nova fonte de questionamento pode resultar no estabelecimento de um novo campo de pesquisa, uma nova interdisciplina. 
Holmes argumentou que, à época em que estava escrevendo seu artigo, a nova área de pesquisa, que atualmente chamamos de Estudos da Tradução, caracterizava o segundo caso e ele abriu espaço para discussão de possíveis nomes para esse novo campo do saber. Aproximadamente uma geração após a publicação do artigo, parece-me que esta tendência integra o primeiro caso: na área dos Estudos da Tradução, podemos ser testemunhas do surgimento de uma nova subárea, um novo ramo, o qual sugiro chamar de Estudos do Tradutor (TranslaTOR Studies).

Para uma definição preliminar, digamos que os Estudos do Tradutor são os estudos acerca dos tradutores (e, claro, dos intérpretes). Naturalmente, todas as pesquisas relacionadas às traduções não-automáticas devem demonstrar que há tradutores por trás das traduções, pessoas por trás de textos. Mas nem toda pesquisa em tradução tem estas pessoas como foco inicial e principal, o ponto de partida, o conceito central da indagação da pesquisa. Exemplos de pesquisa que ilustram esse objetivo são fornecidos abaixo. Certamente, haverá opiniões divergentes a respeito do momento em que as tendências a que me refiro constituem uma subárea distinta em veza de simplesmente constituírem uma ampliação das características dos Estudos da Tradução em geral. Talvez meu esboço demonstre nada mais do que uma mudança

34 de foco nas pesquisas sobre tradução como um todo. Contudo, tais mudanças de foco também podem merecer nossa atenção metateórica. A seguir, apresento uma visão global do que acredito ser uma subárea em emergência, como se fosse uma breve resposta ao artigo original de Holmes e ao mapa por ele relatado.

\section{De volta ao mapa...}

O famoso mapa de Holmes tem circulado em diversas publicações, como em Toury (1995, p. 10). Entretanto, a versão publicada do artigo original de Holmes (1988) não o contém como um diagrama. Curiosamente, algumas versões da figura (como a apresentada por Toury) omite o ramo sobre as políticas da tradução, citado claramente no artigo de Holmes. Abaixo uma versão do mapa incluindo este ramo: 


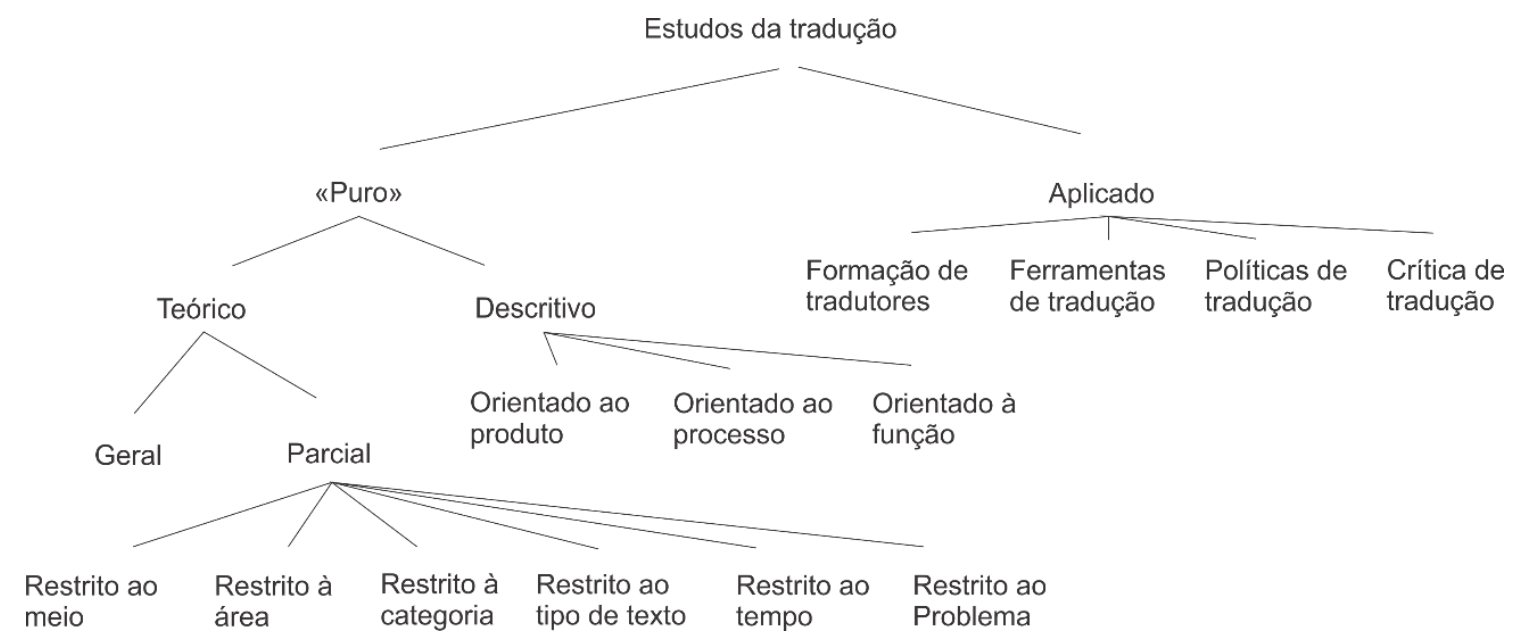

Figura 1. Mapa de Holmes (baseado em HOLMES, 1988)

Naturalmente, o mapa foi bastante comentado anteriormente. Toury (1995, 9f) problematiza a aparente autonomia da principal divisão da pesquisa descritiva orientada ao produto, processo e função, e também a relação entre os estudos "descritivos" e "teóricos". Pym (1998) indica a ausência da pesquisa teórica no mapa (embora Holmes não mencione os estudos da história da tradução e refira-se implicitamente aos tradutores no texto). Lambert (1991) afirma que o mapa deveria ter dado maior importância aos fatores contextuais e pragmáticos. Snell-Hornby (1991) assegura que as categorias relacionadas à subárea "parcial”, os estudos restritos, estão desatualizados, propondo um mapa completamente diferente, que demonstra as relações entre a interdisciplina dos Estudos da Tradução e as disciplinas conexas. Gile (2005, p. 341) lista diversos problemas, principalmente relacionados à categoria "descritiva"; a pesquisa aplicada também pode ser descritiva, por exemplo. Chesterman (2004) também questiona algumas suposições de Holmes acerca da relação entre a construção teórica e a descrição. Entretanto, meu objetivo neste artigo é observar em que medida nossas suposições acerca dos Estudos da Tradução estão representadas no mapa.

As principais diferenças apontadas por Holmes entre os estudos puros e os aplicados, e entre os teóricos e os descritivos, não são importantes para este artigo. Começarei com suas subdivisões dos estudos parciais (em oposição aos estudos gerais). Holmes afirma que estes tratam de aspectos específicos da tradução em detrimento da tradução como um todo. $\mathrm{O}$ primeiro tipo é os estudos restritos ao meio, sendo que Holmes utiliza a noção de meio sob duas formas distintas. No que diz respeito à tradução humana versus a tradução automática, nossa subárea proposta, os Estudos do Tradutor, está certamente implícita. Em termos de mídia escrita versus mídia oral, podemos tornar os Estudos do Tradutor como importantes para ambos. Os 
outros tipos de estudos parciais (restritos por área ou língua, à categoria linguística-textual, tipo de texto, tempo, problema tradutório) não indicam uma importância explícita para os Estudos do Tradutor, uma vez que o foco principal deste tipo de trabalho é o textual. Contudo, no que diz respeito aos estudos restritos ao tempo, podemos, obviamente, focar na história dos tradutores e intérpretes, muitos deles pioneiros culturais.

No contexto dos Estudos Descritivos, Holmes lista as pesquisas orientadas ao produto, processo ou função. Uma vez que os produtos da tradução são textos (inclusive a variante oral), este ramo do mapa não está relacionado inicialmente à nossa subárea. Nos Estudos do Tradutor, os textos são secundários, os tradutores são a fonte primária de estudo; esta prioridade induz a diferentes tipos de questionamento. (Isto não significa negar que a investigação orientada ao produto pode revelar fatos interessantes sobre as pessoas por trás dos textos.)

\section{Sociologia da Tradução}

A orientação do processo, no entanto, é certamente relevante. Holmes relaciona isso com estudos cognitivos do ato de tradução - uma área da pesquisa em tradução que se expandiu 36 consideravelmente desde a sua época. Mas ele não faz nenhuma menção ao processo sociológico no caso da tradução. É verdade, isso é parcialmente implícito no que ele diz sobre o tema da pesquisa orientada para a função, que está relacionada com a recepção das traduções tendo como meta a sociocultura. Holmes ainda sugere a possibilidade do que ele chama de "sociologia da tradução", como uma futura área de pesquisa. Esta é certamente uma declaração profética, à luz da recente "virada sociológica" nos Estudos da Tradução. Sugeri (CHESTERMAN, 2006) que a tal sociologia da tradução era composta por três vertentes:

- $\quad$ a sociologia das traduções, como produtos em um mercado internacional;

- a sociologia dos tradutores; $\mathrm{e}$

- $\quad$ a sociologia do traduzir, isto é, o processo de tradução.

Holmes parece ter previsto apenas a primeira dessas vertentes. A segunda e terceira vertentes são, obviamente, áreas centrais dos Estudos da Tradução atualmente. Para exemplos que tratam tanto de tradutores e intérpretes, ver, por exemplo, HEILBRON, 2000; BACHLEITER/WOLF, 2004; DIRIKER, 2004; INGHILLERI, 2005; LOBO/FUKARI, 2007; KOSKINEN, 2008; DAM/ZETHSEN, 2008; a questão especial (2002) da revista sociológica Actes de la recherche en sciences sociales, n. 144; e da nova revista Translation Studies. 
A sociologia dos tradutores abrange questões como o estatuto de diferentes tipos de tradutores em culturas distintas, a remuneração, condições de trabalho, modelos e hábitos do tradutor, organizações profisssionais, sistemas de acreditação, redes de tradutores, direitos autorais e assim por diante. Questões de um tipo diferente sobre esse assunto são relativas a gênero e orientação sexual, relações de poder, e como esses fatores afetam o trabalho e as atitudes do tradutor. A sociologia dos tradutores também abrange o discurso público da tradução, ou seja, a prova da imagem pública da profissão de tradutor, como se vê, por exemplo, na imprensa, ou em obras literárias em que um dos personagens centrais é um tradutor ou intérprete (ver, por exemplo MAIER, 2006, KURZ/KAINDL, 2005). Com a mesma denominação, eu definiria a pesquisa sobre as atitudes dos tradutores em relação ao seu trabalho, como revelado em ensaios, entrevistas, prefácios e notas de tradutores etc. Aqui também eu definiria o amplo campo de ideologias dos tradutores e da ética da tradução; curiosamente, campos ausentes do mapa Holmes. Uma extensão dessa vertente incluiria o estudo de voluntariado e tradutores ativistas (ver, por exemplo, BAKER, 2006, especialmente o capítulo 7; MUNDAY, 2007).

Neste contexto, gostaria de chamar a atenção para uma ideia inicialmente discutida por Chesterman/Baker (2008). Estamos acostumados a usar o termo "skopos" para denotar o efeito pretendido de uma tradução também podemos fazer uso do termo companheiro "telos" para denotar a motivação pessoal dos tradutores. Isso incluiria as razões pelas quais eles trabalham nesta área em geral, e também o motivo pelo qual traduzem um determinado texto. Tradutores voluntários, em particular, como tradutores ativistas, podem ter teloi que são especialmente interessantes. O trabalho sociológico sobre a teloi dos tradutores (e claro de intérpretes) pode trazer contribuições valiosas para uma melhor compreensão de suas atitudes, objetivos pessoais e ética, e como isso influencia o que e modo como traduzem.

Um incidente recente na Finlândia ilustra outras dimensões da pesquisa sociológica sobre tradutores. Um anúncio de emprego publicado em um jornal, pedindo por candidatos com a seguinte mensagem: "um tradutor falante de russo/intérprete/limpador" [sic!]. A comunidade de tradução finlandesa reagiu imediatamente, com horror, e protestos seguiram. Mas o incidente revela aspectos preocupantes da percepção pública do status do tradutor/intérprete, atitudes em relação aos falantes de russo (o anúncio foi provavelmente destinado aos imigrantes), e exploração comercial. Isso também levantou questões relativas à ética do empregador. Eu me pergunto o quão típico tal anúncio pode ser?

A sociologia do processo de tradução, por outro lado, está relacionada ao estudo das 
fases do ato tradutório: práticas de tradução e procedimentos de trabalho, procedimentos de controle de qualidade e processo de revisão, a cooperação em equipes de tradução, elaboração múltipla, relações com outros agentes, incluindo o cliente, e assim por diante. Um conceito central é o de normas de tradução, que têm estado muito em evidência na pesquisa em tradução especialmente desde Toury (1995). (Para uma discussão mais aprofundada e referências, ver, por exemplo, MOSSOP, 2001 e CHESTERMAN, 2006.)

Já em relação ao ramo aplicado do mapa de Holmes, encontramos três subtipos que são relevantes para os Estudos do Tradutor. Um deles é a formação de tradutores, o que é tão óbvio que nenhum comentário adicional é necessário. O segundo é a política de tradução, o que certamente é uma área dos Estudos do Tradutor. Neste, Holmes escreve:

\begin{abstract}
A tarefa do estudioso da tradução nesta área é prestar aconselhamento informado aos outros na definição do lugar e do papel dos tradutores, o ato de traduzir e traduções na sociedade em geral. Tais questões, por exemplo, como determinar quais trabalhos têm a necessidade de serem traduzidos em uma determinada situação sociocultural, qual a posição social e econômica do tradutor e qual deveria ser, ou [...] qual o papel o ato de traduzir deve desempenhar no ensino e aprendizagem de línguas estrangeiras. ${ }^{5}(1988 / 2000$, p.182)
\end{abstract}

Em retrospectiva, podemos sentir que o tom aqui é um pouco prescritivo. Afinal, também podemos procurar descrever e explicar as políticas de tradução de determinadas instituições (como a União Europeia, por exemplo, ou uma determinada empresa ou município), sem necessariamente dar-lhes conselhos. Estas políticas podem dispor sobre questões, tais como, se uma tradução encomendada deve ser feita por um falante nativo da língua-alvo, ou por um tradutor profissional; se um determinado tipo de tarefa deve ser feito in-house ou por um tradutor freelancer; ou que tipos de procedimentos de arbitragem estão disponíveis em caso de litígio; ou que tipos de serviços de consulta estão disponíveis para o tradutor. Portanto, este tópico de pesquisa se estende ao ramo descritivo de Holmes que também parece incluir aqui alguns dos tópicos que eu listei acima acerca da sociologia de tradutores. Aqui também, a noção de normas é fundamental, especialmente as normas preliminares de Toury, que tratam explicitamente da política de tradução.

O terceiro subtipo aplicado por Holmes é o estudo de auxílios à tradução. Do ponto de vista de como os próprios tradutores usam vários auxílios e recursos, esta pesquisa é claramente parte dos Estudos do Tradutor, sendo parte do estudo acerca dos processos de trabalho do tradutor. O desenvolvimento dos auxílios em si mesmos, tais como a melhoria dos sistemas de memória de tradução, encontram-se fora do nosso subcampo. O último subtipo de Holmes, a 
crítica de tradução, não parece constar dos Estudos do Tradutor.

\section{Rumo a um modelo agente}

O que podemos concluir a partir desta breve pesquisa? Primeiramente, a visão de Holmes sobre os Estudos da Tradução foi mais voltada aos textos, e não para as pessoas que os produzem. Isto não é surpreendente, tendo em conta o seu interesse especial em tradução literária e na pesquisa sobre este assunto. Encontramos conhecimento explícito ou implícito acerca dos Estudos do Tradutor em vários pontos no mapa, mas não de maneira consistente. Nossos pontos de contato estão em diferentes níveis na hierarquia de Holmes. Também foram encontradas algumas lacunas no mapa, principalmente em relação ao âmbito da pesquisa sobre sociologia da tradução, história e ética. Para ser justo, tais pontos de discussão mal tinham surgido em 1972. Usando o mapa de Holmes, é difícil dar uma visão coerente do novo subcampo, então aqui temos uma alternativa (CHESTERMAN, 2006 e em outros).

Presume-se que os Estudos da Tradução são compostos por quatro grandes ramos, a saber: textual, cultural, cognitivo e sociológico. O ramo textual lida com todas as questões textuais e, portanto, consequentemente, situa-se fora dos Estudos do Tradutor. Porém, os outros três ramos são todos importantes para os Estudos do Tradutor, e de fato oferecem uma forma de conceitualizar este subcampo dos Estudos da Tradução. O ramo cultural lida com valores, ética, ideologias, tradições, história, examinando os papéis e as influências de tradutores e intérpretes ao longo da história, como agentes de evolução cultural. O ramo cognitivo trata dos processos mentais, das tomadas de decisão, do impacto das emoções, das atitudes às normas, da personalidade etc. O ramo sociológico lida com o comportamento observável dos tradutores e intérpretes como indivíduos, grupos ou instituições, suas redes sociais, status e processos de trabalho, as suas relações com outros grupos e com a tecnologia relevante, e assim por diante. Todos os três ramos compreendem tanto os estudos teóricos quanto os descritivos, e também os estudos puros e aplicados.

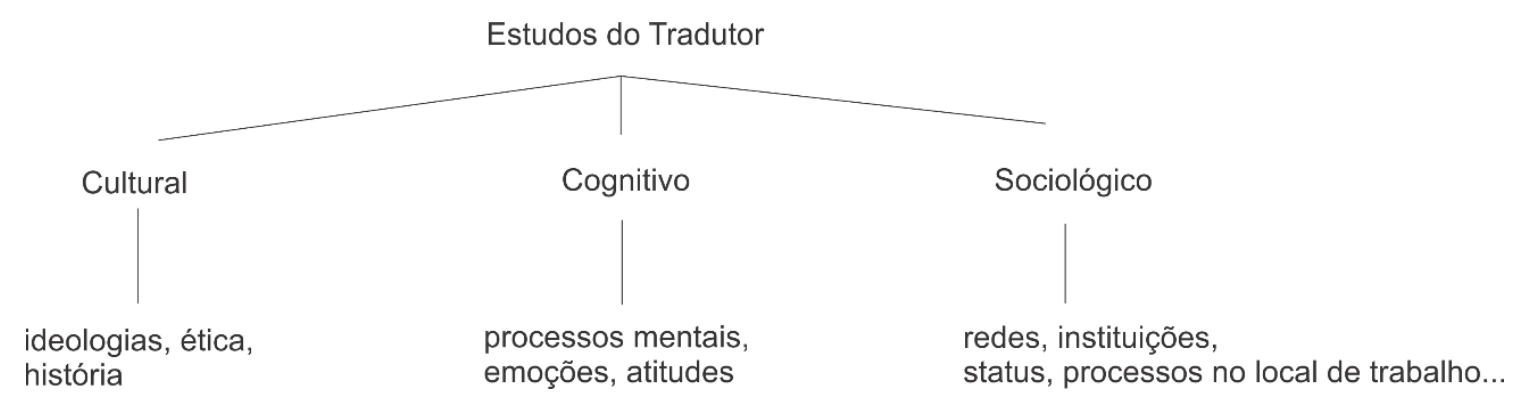

Figura 2. Esboço acerca dos Estudos do Tradutor 
Em termos dos três mundos ontológicos de Popper $^{6}$ (ver POPPER, 1972), os objetos de estudo do ramo cultural estão principalmente no Mundo 3, o mundo dos conteúdos objetivos do pensamento humano que estão em domínio público. Os objetos de estudo do ramo cognitivo fazem parte do Mundo 2, a esfera dos estados mentais. Os objetos de estudo do ramo sociológico estão parcialmente no Mundo 1, o mundo dos fenômenos físicos observáveis (por exemplo, ações, comportamentos), mas fazem parte também do Mundo 2 (ideologias subjetivas e atitudes) e do Mundo 3 (status, a imagem pública). O ramo sociológico é, portanto, ontologicamente o mais complexo. Por esse motivo, pode ser o mais propenso a uma fragmentação futura.

A perspectiva sociológica também nos obriga a ajustar nossos modelos tradicionais do objeto de nossa pesquisa. Eu sugeri que os Estudos da Tradução têm normalmente feito uso de três modelos gerais de tradução (ver CHESTERMAN, 2000). O primeiro é um modelo comparativo, baseado na comparação de dois textos, tais como texto-fonte e texto-alvo ou traduções e não-traduções. O segundo é um modelo de processo, observando as fases do 40 processo de tradução ao longo do tempo, quer em nível cognitivo da tomada de decisão, quer no nível observável do comportamento do tradutor e procedimentos no local trabalho. $\mathrm{O}$ terceiro é um modelo causal, com muitas variantes. No entanto, o tipo de trabalho citado acima sugere que alguns estudiosos estão usando um modelo geral adicional, concentrando-se não em traduções de textos, nem mesmo no processo de tradução, mas nos próprios tradutores e outros agentes envolvidos. Talvez pudéssemos chamar este de o modelo agente.

À luz do esboço anterior, podemos retornar à nossa definição preliminar de Estudos do Tradutor e oferecer uma versão expandida. Os Estudos do Tradutor englobam pesquisas que se concentram, principal e explicitamente, nos agentes envolvidos na tradução, por exemplo, em suas atividades ou atitudes, na sua interação com o meio social e técnico, ou na sua história e influência.

\section{REFERÊNCIAS BIBLIOGRÁFICAS}

BACHLEITER, Norbert; WOLF, Michaela (eds.). Soziologie der literarische Überset-zung. Tübingen: Niemeyer, 2004.

BAKER, Mona. Translation and Conflict. A narrative account. London: Routledge, 2006.

CHESTERMAN, Andrew. A Causal Model for Translation Studies. IN: OLOHAN, Maeve (ed.), Intercultural Faultlines. Manchester: St. Jerome Publishing, 2000, p. 15-27. 
CHESTERMAN, Andrew. Translation as an object of research. IN: KITTEL, Harald et al. (eds.). Übersetzung, Translation, Traduction. Berlin: de Gruyter, 2004, p. 93-100.

CHESTERMAN, Andrew. Questions in the sociology of translation. IN: FERREIRA DUARTE, João; ASSIS Rosa, Alexandra; SERUYA, Teresa (eds.). Translation Studies at the Interface of Disciplines. Amsterdam: Benjamins, 2006, p. 9-27.

CHESTERMAN, Andrew; BAKER, Mona Ethics of renarration. An interview with Mona Baker. In Cultus 1, 2008.

DAM, Helle V.; ZETHSEN, Karen K. Translator Status. A study of Danish Company Translators. IN: The Translator, 2008, 14, 1, p. 71-96.

DIRIKER, Ebru. De-/re-contextualizing conference interpreting: interpreters in the ivory tower? Amsterdam: Benjamins, 2004.

GILE, Daniel. La traduction: la comprendre, l'apprendre. Paris: Presses Universitaires de France, 2005.

HEILBRON, Johan. Translation as a Cultural World System. IN: Perspectives, 2000, 8, 1, p. 9-26.

HOLMES, James S. The Name and Nature of Translation Studies. IN: Holmes, J.S., 1988.

Translated! Papers on Literary Translation and Translation Studies. Amsterdam: Rodopi, p. 67-80. Reprinted e.g. in VENUTI, L. (ed.). The Translation Studies Reader. London: Routledge, 2000, p. 172-185.

INGHILLERI, Moira (ed.). Bourdieu and the Sociology of Translation and Interpret-ing. Special issue of The Translator, 2005, 11, 2.

KOSKINEN, Kaisa. Translating Institutions. Manchester: St. Jerome Publishing, 2008.

KURZ, Ingrid/Kaindl, Klaus (eds.). Wortklauber, Sinnverdreher, Brückenbauer? DolmetscherInnen und ÜbersetzerInnen als literarische Geschöpfe. Vienna: Lit Verlag, 2005.

LAMBERT, José. Shifts, Oppositions and Goals in Translation Studies: Towards a Genealogy of Concepts. IN: VAN LEUVEN-ZWART, Kitty; NAAIJKENS, Ton (eds.). Translation Studies: The State of the Art. Amsterdam: Rodopi, 1991, p. 25-37.

MAIER, Carol. The translator as theoros. In HERMANS, Theo (ed.), Translating Others, vol. 1. Manchester: St. Jerome Publishing, 2006, p. 163-180.

MOSSOP, Brian Revising and Editing for Translators. Manchester: St. Jerome Publishing, 2001

MUNDAY, Jeremy (ed.). Translation as Intervention. London: Continuum, 2007.

POPPER, Karl R. Objective Knowledge. An Evolutionary Approach. Oxford: Clarendon Press, 1972. 
PYM, Anthony. Method in Translation History. Manchester: St. Jerome Publishing, 1998.

SNELL-HORNBY, Mary. Translation Studies - Art, Science or Utopia? IN: VAN LEUVENZWART, Kitty/NAAIJKENS, Ton (eds.). Translation Studies: The State of the Art. Amsterdam: Rodopi, 1991, p. 13-23.

TOURY, Gideon. Descriptive Translation Studies and Beyond. Amsterdam: Benjamins, 1995.

WOLF, Michaela/Fukari, Alexandra (eds.). Constructing a Sociology of Translation. Amsterdam: Benjamins, 2007.

\section{RECEBIDO EM 05/12/2014 \\ ACEITO EM 12/01/2015}

\footnotetext{
1 Disponível em: http://download2.hermes.asb.dk/archive/download/hermes-42-2-chesterman_net.pdf. Acesso: nov. 2014.

2 Tradução autorizada pelo autor em 28/05/2014 via e-mail e pela revista Hermes em 19/06/2014 via e-mail.

$42 \quad{ }^{3}$ Lattes Patrícia Rodrigues Costa. Disponível em: http://lattes.cnpq.br/9546437584230118. Acesso: jan. 2015.

${ }^{4}$ Lattes Rodrigo D’Avila Braga Silva. Disponível em: http://lattes.cnpq.br/1746993519090773. Acesso: jan. 2015.

5 "The task of the translation scholar in this area is to render informed advice to others in defining the place and role of translators, translating, and translations in society at large: such questions, for instance, as determining what works need to be translated in a given socio-cultural situation, what the social and economic position of the translator is and should be, or [...] what part translating should play in the teaching and learning of foreign languages." (tradução nossa)
}

6 POPPER, Karl. Three Worlds. University of Michigan, 1978. Disponível em: http://tannerlectures.utah.edu/_documents/a-to-z/p/popper80.pdf. Acesso: nov. 2014. 